\title{
Evaluation of Medicated Pharyngeal Pack for Prevention of Postoperative Sore Throat following Nasal Septal Surgery
}

Tarique Ahmed Maka ${ }^{1}$, Akeel Ur Rehman², Sajid Ali ${ }^{3}$

\begin{abstract}
Objective: To compare the difference in frequency of postoperative sore throat, dysphagia, hoarseness and cough after nasal septal surgery between pharyngeal packings soaked in normal saline, soluble aspirin or ketorolac.

Study Design: A comparative study.

Place and Duration of Study: The study was carried at ENT Department of Combined Military Hospital, Risalpur from July 2017 to June 2018.

Materials and Methods: The study was performed on 180 patients of both genders, aged between 20-50 years. Cases were randomly allocated into three groups of 60 each. In group A (control), postoperative pharyngeal packing was done with ribbon gauze impregnated with $50 \mathrm{ml}$ normal saline, in group B (soluble aspirin group) packing was done with gauze impregnated in $50 \mathrm{ml}$ of normal saline in which $300 \mathrm{mg}$ of soluble aspirin was dissolved, whereas in group $\mathrm{C}$ (ketorolac group) packing was done with gauze impregnated in $50 \mathrm{ml}$ of normal saline in which $30 \mathrm{mg}$ of ketorolac was dissolved.

Results: In group A, 10 patients (16.7\%) complained of sore throat, 8 (13.3\%) dysphagia, 11 (18.3\%) hoarseness and $12(20 \%)$ cough. In group B, $4(6.7 \%)$ patients complained of sore throat, 3 (5\%) dysphagia, $3(5 \%)$ hoarseness and 4 (6.7\%) cough whereas in group C, $3(5 \%)$ patients complained sore throat, $1(1.7 \%)$ dysphagia, $2(3.3 \%)$ hoarseness and $4(6.7 \%)$ cough. All parameters were significantly raised $(p<0.001)$ in group $A$ as compared to group $B$ and $C$ whereas there was no significant difference found in the parameters between group $B$ and C except dysphagia which was significantly lower $(p<0.001)$ in group C as compared to group B.

Conclusion: Use of soluble aspirin or ketorolac impregnated pharyngeal packing significantly reduced frequency of post-operative sore throat, dysphagia, hoarseness and cough as compared to simple normal saline impregnated packing among patients undergoing nasal surgery.
\end{abstract}

Key Words: Ketorolac, Pharyngeal Packing, Soluble Aspirin, Sore Throat.

How to cite this: Maka TA, Rehman A, Ali S. Evaluation of Medicated Pharyngeal Pack for Prevention of Postoperative Sore Throat following Nasal Septal Surgery. Life and Science. 2020; 1(1): 33-36. doi: https://doi.org/10.37185/LnS.1.1.16

\section{Introduction}

Incidence of sore throat following laryngoscopy and intubation remains distressingly high. Many patients do not complain much about the pain following surgery at the surgical site, yet they are distressed by postoperative sore throat (POST). ${ }^{1}$ The incidence of sore throat, hoarseness and dysphagia has been

\footnotetext{
${ }^{1,2}$ Department of ENT

Combined Military Hospital, Risalpur

Department of Physiology

${ }^{3}$ Army Medical College, Rawalpindi

Correspondence:

Dr. Tarique Ahmed Maka

Department of ENT

Combined Military Hospital, Risalpur

Email: tariqmaka@yahoo.com

Funding Source: NIL; Conflict of Interest: NIL

Received: Sep 05, 2018; Revised: Oct 16, 2019

Accepted: Dec 05, 2019
}

investigated to be as high as $80 \%$ following endotracheal intubation and pharyngeal packing in nasal surgeries. ${ }^{2}$ Various remedial measures have been advocated to decrease undesirable effects of endotracheal intubation including use of conventional polyvinyl chloride (PVC) endotracheal tube rather than the red rubber tube, single puff beclomethasone inhalation and instillation of lidocaine in endotracheal tube cuff instead of air. ${ }^{3}$

In most of the surgical procedures involving the nose and paranasal sinuses, the feared complication is aspiration of blood and tissue debris into the trachea or oesophagus. ${ }^{4}$ The blood which is accidently swallowed during the surgery exerts potent emetic effect that leads to postoperative nausea and vomiting (PONV), a complication affecting up to $30 \%$ of all surgical procedures involving nose and 
paranasal sinuses. ${ }^{5}$ Pharyngeal packing is one of the methods adopted by the surgeons to prevent aerodigestive aspiration of blood and secretions. Apart from prevention of PONV, pharyngeal packing soaked in normal saline significantly associated with increased incidence of POST, dysphagia and hoarseness. Use of various pharmacological agents have been advocated in the literature to reduce the incidence of POST, hoarseness and dysphagia such as beclomethasone inhalation, gargling with nonsteroidal anti-inflammatory drugs (NSAIDs) and azulene sulfonate ${ }^{6}$ as well as the use of tenoxicam soaked pharyngeal pack for the prophylaxis of POST. Soluble aspirin is an extremely cheap and easily available drug which easily dissolves in saline. Similarly, ketorolac is a water soluble NSAID. Pharyngeal pack soaked in saline containing soluble aspirin or ketorolac may reduce the occurrence of POST, dysphagia and hoarseness as quoted above. ${ }^{7}$

The aim of current study was to compare the frequency of postoperative sore throat, dysphagia, hoarseness and cough associated with use of pharyngeal pack soaked in normal saline, soluble aspirin or ketorolac following nasal surgery.

\section{Materials and Methods}

The study was conducted at ENT Department of Combined Military Hospital, Risalpur from July 2017 to June 2018 with permission of the hospital's ethical committee. Sample size of 174 was calculated with $80 \%$ power of test and $95 \%$ significance level while taking expected frequency of sore throat as about $39 \%$ in group $A$ and $19 \%$ in groups B and C. However, we have included 180 patients in the study so that 60 patients could be allocated to each group. ${ }^{2}$ Patients of both genders undergoing nasal surgery, age ranging between 20-50 years were selected by nonprobability consecutive sampling. They were randomly allocated into three groups of 60 each using lottery method. Inclusion criteria were patients in American Society of Anesthesiologists (ASA) grade I \& II and Mallampati score I \& II, healthy adults undergoing uncomplicated elective nasal surgeries. Exclusion criteria were ASA grade III \& IV, Mallampati score III \& IV, smokers, allergic to NSAIDs, suffering from bleedings disorders, undergoing emergency surgery and having preexisting sore throat or laryngotracheal disease. A written informed consent was obtained from all patients to participate in the study.

In all patients, uniform surgical technique was used, and all were intubated with PVC endotracheal tube filled with just enough air. After properly securing the endotracheal tube, in group A (control) pharyngeal packing was done with ribbon gauze measuring 1 meter length and 1 centimeter in breadth impregnated in $50 \mathrm{ml}$ of normal saline, in group B (soluble aspirin group) pharyngeal packing was done with same length of gauze as in group $A$ impregnated in $50 \mathrm{ml}$ of distilled water in which $300 \mathrm{mg}$ aspirin was dissolved whereas in group C (ketorolac group) pharyngeal packing was done with same length of gauze as in group A \& B impregnated in $50 \mathrm{ml}$ of distilled water in which $30 \mathrm{mg}$ of ketorolac was dissolved. On completion of surgery, patients were reversed from anesthesia, proper suction was carried out under direct vision, pharyngeal pack was removed and patients were extubated in awake state. Patients remained under observation and were assessed for presence of sore throat, dysphagia, hoarseness and cough 6 hours postoperatively. Due consideration was given to the severity of complaints and their association with daily activity like speaking, drinking and eating. The data was recorded on a proforma for further statistical analysis.

The data was analyzed by IBM SPSS (Statistical Package for the Social Sciences) version 21. Age has been described as mean and standard deviation (SD). Gender, post-operative sore throat, dysphagia, hoarseness and cough have been presented as frequency and percentages. To compare the difference of age between groups, one-way analysis of variance (ANOVA) was applied whereas for other categorical variables, chi-square test was applied. A $p$-value of $<0.05$ was considered statistically significant.

\section{Results}

The mean age of the patients in group $A$ was $35.73 \pm$ 9.84 years, in group B was $34.43 \pm 10.05$ years whereas in group $C$ it was $34.03 \pm 10.77$ years (Table 1). In group $A, 10$ patients (16.7\%) complained of sore throat, 8 (13.3\%) dysphagia, 11 (18.3\%) hoarseness and 12 (20\%) cough. In group B, 4 (6.7\%) patients complained of sore throat, $3(5 \%)$ dysphagia, 3 (5\%) hoarseness and 4 (6.7\%) cough whereas in group C, $3(5 \%)$ patients complained of 
sore throat, 1 (1.7\%) dysphagia, 2 (3.3\%) hoarseness and $4(6.7 \%)$ cough. All parameters were significantly raised $(p<0.001)$ in group $A$ as compared to group $B$ \& $C$ (Table 2). However, there was no significant difference found in all parameters between group $B$ and $C$ except dysphagia which was significantly lower $(p=0.037)$ in group $\mathrm{C}$ as compared to group B (Table 3).

\begin{tabular}{|c|c|c|c|}
\hline \multirow[t]{2}{*}{ Variables } & \multicolumn{2}{|c|}{ Groups } & \multirow[b]{2}{*}{ Ketorolac } \\
\hline & Control & Aspirin & \\
\hline Age (years) & $35.73 \pm 9.84$ & $34.43 \pm 10.05$ & $34.03 \pm 10.77$ \\
\hline \multirow{2}{*}{ Gender } & 37 (61.67\%) & 33 (55\%) & 32 (53.33\%) \\
\hline & 23 (38.33\%) & 27 (45\%) & $28(46.67 \%)$ \\
\hline \multicolumn{4}{|c|}{$\begin{array}{l}\text { Table 2: Frequency of Study Variables among } \\
\text { Groups }\end{array}$} \\
\hline \multirow[t]{2}{*}{ Variables } & \multicolumn{2}{|c|}{ Groups } & \\
\hline & Control & Aspirin & Ketorolac \\
\hline Sore Throat & $16.7 \%$ & $6.7 \%$ & $5 \%$ \\
\hline Dysphagia & $13.3 \%$ & $5 \%$ & $1.7 \%$ \\
\hline Hoarseness & $18.3 \%$ & $5 \%$ & $3.3 \%$ \\
\hline Cough & $20 \%$ & $6.7 \%$ & $6.7 \%$ \\
\hline \multicolumn{4}{|c|}{ Table 3: Comparison Variables between different Groups } \\
\hline \multirow[t]{2}{*}{ Variables } & & alue & \\
\hline & $\begin{array}{c}\text { Control } \\
\text { vs } \\
\text { Aspirin }\end{array}$ & $\begin{array}{l}\text { Control } \\
\text { vs } \\
\text { Ketorolac }\end{array}$ & $\begin{array}{c}\text { Aspirin } \\
\text { vs } \\
\text { Ketorolac }\end{array}$ \\
\hline Sore Throat & $<0.001$ & $<0.001$ & 0.698 \\
\hline Dysphagia & $<0.001$ & $<0.001$ & 0.037 \\
\hline Hoarseness & $<0.001$ & $<0.001$ & 0.736 \\
\hline Cough & $<0.001$ & $<0.001$ & 0.779 \\
\hline
\end{tabular}

\section{Discussion}

Apart from possible reduction in PONV, placement of a normal saline impregnated pharyngeal pack itself carries risk of POST, dysphagia, hoarseness and cough. ${ }^{8}$ Therefore, the present study was conducted to assess the possible benefits of placement of either aspirin or ketorolac impregnated pharyngeal pack during nasal surgeries instead of placement of simple normal saline soaked pack.

The results of the present study revealed significant reduction $(p<0.001)$ in POST, dysphagia, hoarseness and cough using soluble aspirin or ketorolac in pharyngeal packing as compared to simple normal saline packing. Aspirin is an extensively used analgesic with antipyretic and anti-inflammatory properties available in different formulations. It is used for the treatment of fever and various types of pain. ${ }^{9}$ Some studies have reported affectivity of gargles with soluble aspirin in relieving pain in throat lesions. In 2006, Agarwal et al. conducted a study to evaluate the efficacy of dispersible aspirin and benzydamine hydrochloride gargles for reducing incidence and severity of POST. Their results revealed that gargling with dispersible aspirin is associated with significantly decreased incidence of POST which is consistent with our results. In another study Chattopadhyay et al. compared the efficacy of preoperative gargles for 30 second with aspirin and magnesium sulfate for the prophylaxis of POST. The authors reported significant attenuation in the frequency and severity of POST among both groups without any adverse effect however, results of magnesium sulfate were much better as compared to aspirin. ${ }^{10}$ another study was conducted to evaluate the role of various pharmacologic agents including aspirin, ketamine, azulene gargle and benzydamine gargle in reduction of POST. while the authors found a significant reduction in the incidence and severity of POST using all agents, but their result were most promising with aspirin and ketamine. ${ }^{11}$

Ketorolac is a potent analgesic with antiinflammatory and antipyretic activity. The drug is rapidly effective against pain and acts through inhibition of prostaglandin synthesis. Its rapid therapeutic effect can be achieved locally through absorption from mucosal membrane. In 2016, Yang et al investigated the effect of ketorolac spray to prevent endotracheal intubation induced sore throat. They demonstrated significant reduction in post intubation sore throat among patients who were intubated with ketorolac tromethamine sprayed endotracheal tubes. ${ }^{12}$ In another study, researchers compared the effect of dexamethasone and ketorolac on the incidence of post intubation hoarseness and sore throat. They found insignificant differences in the incidence of hoarseness in both groups however, dexamethasone significantly reduced $(p<0.001$ ) the incidence of post intubation sore throat whereas ketorolac did not. ${ }^{13}$ The results of this study are contradictory to our results whereby we found significant reduction in both POST and hoarseness with the use of ketorolac impregnated pharyngeal packs.

\section{Conclusion}

The use of soluble aspirin or ketorolac impregnated 
pharyngeal packing significantly reduced frequency of post-operative sore throat, dysphagia, hoarseness and cough as compared to simple normal saline impregnated packing among patients undergoing nasal surgery. Based on our findings, it is recommended that either soluble aspirin or ketorolac impregnated gauze packs may be used for pharyngeal packing in various nasal and paranasal sinuses surgeries to prevent incidence of postoperative complications associated with pharyngeal packing and intubation. Minimizing post-operative complication rate will facilitate early recovery of the patients and improve their quality of life.

\section{REFERENCES}

1. Liu L, Yue H, Li J. Comparison of three tracheal intubation techniques in thyroid tumor patients with a difficult airway: a randomized controlled trial. Med Princ Pract. 2014; 23: 448-52.

2. Rizvi MM, Singh RB, Rasheed MA, Sarkar A. Effects of different types of pharyngeal packing in patients undergoing nasal surgery: A comparative study. Anesth Essays Res. 2015; 9: 230-7.

3. Sharma MU, Gombar S, Gombar KK, Singh B, Bhatia N. Endotracheal intubation through the intubating laryngeal mask airway (LMA-Fastrach): A randomized study of LMAFastrach wire-reinforced silicone endotracheal tube versus conventional polyvinyl chloride tracheal tube. Indian J Anaesth. 2013; 57: 19-24.

4. Bajwa SJ. Prevention of aspiration of blood with a unique pharyngeal packing method. Anesth Essays Res. 2012; 6: 251-2.

5. Meco BC, Ozcelik M, Yildirim Guclu C, Beton S, Islamoglu $Y$,
Turgay A, et al. Does Type of Pharyngeal Packing during Sinonasal Surgery Have an Effect on PONV and Throat Pain? Otolaryngol Head Neck Surg. 2016; 154: 742-7.

6. Razavi M, Gilani MT, Bameshki AR, Behdani R, Khadivi E, Bakhshaee M. Pharyngeal Packing during Rhinoplasty: Advantages and Disadvantages. Iran J Otorhinolaryngol 2015; 27:423-8

7. Al-Jandan BA, Syed FA, Zeidan A, Marei HF, Farooq I. Pharyngeal pack placement in minor oral surgery: $A$ prospective, randomized, controlled study. Ear Nose Throat J. 2018; 97: E18-E21.

8. Korkut AY, Erkalp K, Erden V, Teker AM, Demirel A, Gedikli O, et al. Effect of pharyngeal packing during nasal surgery on postoperative nausea and vomiting. Otolaryngol Head Neck Surg. 2010; 143: 831-6.

9. Voelker M, Schachtel BP, Cooper SA, Gatoulis SC. Efficacy of disintegrating aspirin in two different models for acute mild-to-moderate pain: sore throat pain and dental pain. Inflammopharmacology. 2016; 24: 43-51.

10. Chattopadhyay S, Das A, Nandy S, RoyBasunia S, Mitra T, Halder PS, et al. Postoperative Sore Throat Prevention in Ambulatory Surgery: A Comparison between Preoperative Aspirin and Magnesium Sulfate Gargle - A Prospective, Randomized, Double-blind Study. Anesth Essays Res. 2017; 11: $94-100$

11. Kalil DM, Silvestro LS, Austin PN. Novel preoperative pharmacologic methods of preventing postoperative sore throat due to tracheal intubation. AANA J. 2014; 82: 188-97.

12. Yang HL, Liu FC, Tsai SC, Tsay PK, Lin HT, Liu HE. Ketorolac Tromethamine Spray Prevents PostendotrachealIntubation-Induced Sore Throat after General Anesthesia. Biomed Res Int. 2016; 2016: 4582439.

13. Yang C, Jung SM, Bae YK, Park SJ. The effect of ketorolac and dexamethasone on the incidence of sore throat in women after thyroidectomy: a prospective double-blinded randomized trial. Korean J Anesthesiol. 2017; 70: 64-71. 